\title{
APLIKASI MODEL PEMBELAJARAN CONTEXTUAL TEACHING AND LEARNING (CTL) DALAM PENINGKATAN KEMAMPUAN KONEKSI MATEMATIS SISWA
}

\section{CONTEXTUAL TEACHING AND LEARNING (CTL) IN IMPROVING CONNECTION ABILITY MATH STUDENTS}

\author{
SURIYANI ${ }^{1}$, ROHANI ${ }^{2}$, INDAH FITRIA RAHMA ${ }^{3}$ \\ ${ }^{123}$ Program Studi Pendidikan Matematika, FKIP Universitas Labuhanbatu \\ Jalan Sisingamangaraja No. 126A, KM. 3,5 Aek Tapa Rantauprapat \\ email:1suryani.jahwa@yahoo.com,2pasariburohani@gamail.com,3indahfitria286@gmail.com
}

\begin{abstract}
Abstrak
Penelitian ini bertujuan untuk mengetahui apakah terdapat peningkatan kemampuan koneksi matematis siswa melalui model pembelajaran CTL (Contextual Teaching and Learning), dan untuk mengetahui apakah peningkatan kemampuan koneksi matematis siswa melalui model pembelajaran CTL (Contextual Teaching and Learning) lebih baik dari pada model pembelajaran konvensional.. Sampel penelitian di ambil 2 kelas yang ditentukan dengan teknik random cluster sampling, yaitu kelas XI IPA 3 sebanyak 30 siswa sebagai kelas eksperimen dan kelas XI IPA 2 sebanyak 30 siswa sebagai kelas kontrol. Instrument yang digunakan dalam penelitian ini adalah tes kemampuan koneksi matematis siswa dalam bentuk uraian. Data rata-rata pre-test kelas eksperimen yaitu 40,87 dan rata-rata pre-test kelas kontrol yaitu 40,58. Setelah diberikan perlakuan pada masing-masing kelas diperoleh data rata-rata post-test pada kelas eksperimen sebesar 61,70 dan kelas kontrol sebesar 52,40. Berdasarkan hasil pengujian uji t diperoleh nilai $\operatorname{sig}<\operatorname{taraf} \operatorname{sig}(\alpha=0,05)$ untuk $\mathrm{dk}=58$ yaitu $0,000<0,05$ yang artinya bahwa terdapat perbedaan kemampuan koneksi matematis siswa antara kelas eksperimen dan kelas kontrol dengan kata lain terdapat peningkatan kemampuan koneksi matematis siswa yang diajar menggunakan model CTL (Contextual Teaching and Learning). Berdasarkan uji $\mathrm{N}$-gain pada kelas eksperimen diperoleh indeks gain sebesar 0,53 dengan karakteristik sedang dan pada kelas kontrol diperoleh indeks gain sebesar 0,3 dengan karakteristik rendah.
\end{abstract}

Kata Kunci: Model Pembelajaran CTL (Contextual Teaching And Learning), Kemampuan Koneksi Matematis Siswa

\begin{abstract}
This study aims to determine whether there is an increase in students 'mathematical connection ability through CTL (Contextual Teaching and Learning) model, and to know whether the improvement of students' mathematical connection ability through CTL (Contextual Teaching and Learning) learning model is better than the conventional learning model. The sample of research was taken 2 classes determined by random cluster sampling technique, that is class XI IPA 3 of 30 students as experiment class and class XI IPA 2 as 30 students as control class. Instrument used in this research is test of student's mathematical connection ability in the form of description. The average pre-test of the experimental class is 40.87 and the control group's pre-test average is 40.58 . After the treatment was given to each class, the average post-test data in the experimental class was 61.70 and the control class was 52.40. Based on the result of $t$ test, we get the sig $<\operatorname{sig}(\alpha=0,05)$ value for $d k=58$ that is $0,000<0,05$ which means that there is difference of mathematical connection ability of the students between the experimental class and the control class in other words there is an increase of connection capability mathematical students taught using the CTL model (Contextual Teaching and Learning). Based on the $\mathrm{N}$-gain test in the experimental class obtained a gain index of 0.53 with medium characteristics and on the control class obtained a gain index of 0.3 with low characteristics.
\end{abstract}

\section{Keywords: CTL Learning Model (Contextual Teaching And Learning), Student Mathematical Connection Ability}

Suriyani', Rohani', Indah Fitria Rahma ${ }^{3}$

Aplikasi Pembelajaran CTL (Contextual Teaching and Learning) dalam Peningkatan Kemampuan Koneksi Matematis Siswa 


\section{Pendahuluan}

Matematika merupakan ilmu yang mempunyai ciri-ciri khusus, salah satunya adalah koneksi dalam matematika yang bersifat deduktif aksiomatis yang berkenaan dengan ide-ide, konsep-konsep, dan simbol-simbol yang abstrak serta tersusun secara hierarkis. Salah satu rendahnya kualitas koneksi dalam matematika ini disebabkan umumnya guru mentransfer ilmunya langsung kepada siswa, dengan kata lain guru yang aktif sedangkan siswa pasif selama belajar. Koneksi matematis itu sendiri berasal dari kata connection (hubungan) sehingga koneksi matematis yaitu keterkaitan antara internal dan eksternal. Dimana internal adalah keterkaitan yang berhubungan dengan matematika itu sendiri dan eksternal yaitu keterkaitan antara matematika dengan kehidupan sehari - hari. Padahal perlu disadari bahwa proses penyelesaian masalah merupakan tujuan utama dalam pembelajaran pemecahan masalah matematika.

Berkaitan dengan hal tersebut, setelah peneliti melakukan observasi pada tanggal 26 April 2017 proses pembelajaran matematika yang dilaksanakan di kelas XI di SMA Negeri 1 Silangkitang dengan melakukan wawancara dengan guru matematika yang bernama Eva Anggraini S.Pd ditemukan permasalahan antara lain sebagai berikut : 1). Siswa cenderung kurang mampu dalam menggunakan rumus 2). Kemampuan siswa dalam memahami dan menjawab soal yang diberikan guru masih rendah, 3). Beberapa siswa cenderung bergantung pada guru dan temannya dalam menjawab soal-soal yang diberikan, 4). Siwa tidak aktif pada saat pembelajaran matematika berlangsung, 5). Masalah-masalah tersebut disebabkan karena guru masih menggunakan model pembelajaran konvensional. Masalah lain juga dikarenakan kurangnya minat siswa dalam mempelajari matematika. 6). Siswa cenderung menganggap matematika merupakan ilmu yang sulit. Untuk mengatasi masalah tersebut maka perlu digunakan pembelajaran yang tepat sehingga dapat meningkatkan kemampuan koneksi matematis siswa.

Koneksi Matematis adalah bagian penting yang harus mendapatkan penekanan di setiap jenjang pendidikan [2]. Sedangkan menurut [3] Kemampuan koneksi matematis merupakan kemampuan mendasar yang harus dimiliki oleh siswa sekolah dasar. Pentingnya kemampuan koneksi matematika terkandung dalam tujuan pembelajaran matematika sekolah dasar yaitu memahami konsep matematika, menjelaskan keterkaitan antar konsep dan mengaplikasikan konsep atau algoritma, secara luwes, akurat, efisien, dan tepat, dalam pemecahan masalah. NCTM menyatakan tujuan koneksi matematis diberikan pada siswa di sekolah menengah adalah agar siswa dapat : Mengenali representasi yang ekuivalen dari suatu konsep yang sama, Mengeali hubunngan prosedur satu representasi ke prosedur representasi yang ekuivalen, Menggunakan dan menilai koneksi beberapa topik matematika, Menggunakan dan menilai koneksi antara matematika dan disiplin ilmu lain.

Upaya dalam menyikapi rendahnya koneksi matematis siswa bisa ditempuh melalui pemilihan pembelajaran. Untuk mencapai tujuan pembelajaran diatas perlulah dicari alternatif pembelajaran yang dapat memberikan kesempatan kepada siswa untuk mengungkapkan ide/gagasan matematika secara optimal serta menumbuhkan koneksi matematis sehingga siswa lebih berfikir dalam belajar matematika. Salah satu model pembelajaran yang diterapkan dalam proses pembelajaran matematika adalah Contextual Teaching and Learning (CTL).

Pendekatan pembelajaran CTL merupakan salah satu alternatif pilihan pendidik dalam proses pembelajaran untuk mencapai tujuan yang telah ditetapkan. Model pembelajaran Contextual Teaching and Learning adalah konsep belajar yang membantu guru mengaitkan antara materi yang di ajarkan dengan situasi dunia nyata siswa dan mendorong siswa membuat hubungan antara pengetahuan yang dimilikinya dengan penerapannya dalam kehidupan mereka sehari-hari. Rumusan masalah dalam penelitian ini adalah apakah peningkatan kemampuan koneksi matematis siswa melalui model pembelajaran CTL (Contextual Teaching and Learning) lebih baik dari pada model pembelajaran konvensional?

\section{Metode Penelitian}

Penelitian ini adalah penelitian quasi eksperimen. Dalam penelitian ini digunakan dua kelompok, yaitu kelompok yang memperoleh perlakuan pembelajaran matematika dengan menggunakan model pembelajaran Contextual Teaching and Lerning (CTL) yang disebut kelompok eksperimen dan kelompok yang memperoleh pembelajaran matematika dengan menggunakan model pembelajaran biasa yang disebut kelompok kontrol. Lokasi penelitian berada di SMA Negeri I Silangkitang, Labuhanbatu Selatan. Adapun waktu penelitian dilaksanakan pada tanggal 24 Juli 2017

Suriyani', Rohani', Indah Fitria Rahma ${ }^{3}$

Aplikasi Pembelajaran CTL (Contextual Teaching and Learning) dalam Peningkatan Kemampuan Koneksi Matematis Siswa 
s/d 26 Juli 2017 dengan setiap kali pertemuan 2 x 45 menit. Desain perlakuan dapat dilihat pada Tabel 1.

Tabel 1. Desain Perlakuan

\begin{tabular}{|c|c|c|}
\hline Kelompok & Perlakuan & Tes \\
\hline $\mathrm{E}$ & $\mathrm{X}_{\mathrm{E}}$ & $\mathrm{T}$ \\
\hline $\mathrm{K}$ & $\mathrm{X}_{\mathrm{K}}$ & $\mathrm{T}$ \\
\hline
\end{tabular}

Keterangan :

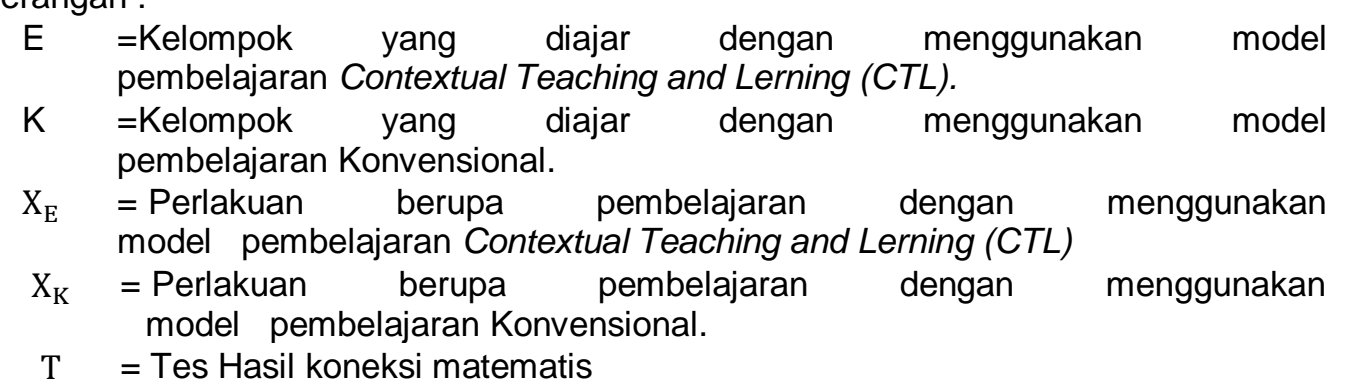

Sampel pada penelitian ini adalah siswa XI IPA 3 yang berjumlah 30 siswa sebagai kelas eksperimen dan XI IPA 2 yang berjumlah 30 siswa sebagai kelas kontrol dengan total sampel 60 siswa. Instrumen yang digunakan dalam penelitian ini adalah tes koneksi matematis siswa sebanyak 5 soal yang digunakan untuk pre-test dan post-test. Analisis yang digunakan untuk pengujian hipotesis adalah: 1) Uji t yaitu independent sample t test dengan menggunakan SPSS untuk melihat terdapat tidaknya peningkatan kemampuan koneksi matematis siswa, namun sebelum dilakukan uji terlebih dahulu dilakukan uji normalitas menggunakan uji chi kuadrat dan homogenitas menggunakan uji $F, 2$ ) Uji $N$-Gain untuk melihat apakah peningkatan kemampuan koneksi matematis yang diajar menggunakan model CTL lebih baik dari pada yang diajar menggunakan model konvensional.

\section{Hasil Penelitian dan Pembahasan Hasil Kemampuan Koneksi Matematis Siswa Kelas Eksperimen}

Berdasarkan pre-test yang diberikan diperoleh rata-rata kelas eksperimen adalah 40,87 dengan standart deviasi sebesar 8,24 dan mengalami kenaikan rata-rata post-test menjadi 61,70 dengan standart deviasi sebesar 7,22 serta kenaikan rata-ratanya sebesar 20,83 dengan standart deviasi sebesar 7,80 serta memiliki persentase kenaikan sebesar $50,98 \%$. Untuk memperjelas hasil rata-rata pre-test dan post-test kelas eksperimen dapat dilihat pada gambar histogram berikut ini:

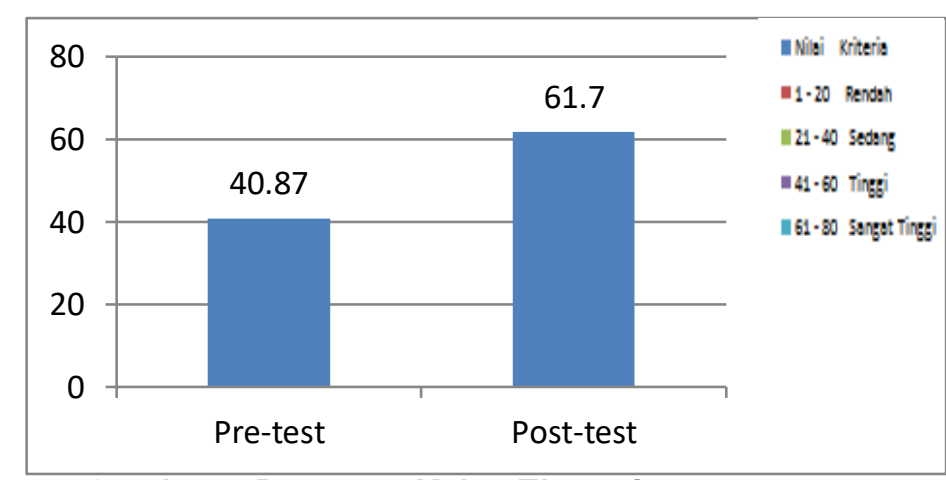

Gambar 1 Rata-rata Kelas Eksperimen

Berdasarkan gambar 1 bahwa rata-rata pre-test kelas eksperimen adalah 40,87 dengan kriteria sedang dan rata-rata post-test kelas eksperimen adalah 61,7 dengan kriteria sangat tinggi. Sedangkan untuk melihat kriteria peningkatan kelas eksperimen dapat dilihat pada tabel 4 berikut ini:

Tabel 2. Hasil $\mathbf{N}$-gain Kelas Eksperimen

\begin{tabular}{|c|c|c|}
\hline $\mathbf{N}$ & Indeks Gain & Kriteria \\
\hline 30 & 0,53 & Sedang \\
\hline
\end{tabular}

Suriyani', Rohani', Indah Fitria Rahma ${ }^{3}$

Aplikasi Pembelajaran CTL (Contextual Teaching and Learning) dalam Peningkatan Kemampuan Koneksi 
Berdasarkan tabel 4 indeks gain sebesar 0,53 dengan kriteria sedang yang artinya bahwa peningkatan kemampuan koneksi matematis siswa kelas XI SMA Negeri 1 Silangkitang yang diajar menggunakan model CTL (Contextual Teaching and Learning) adalah sedang.

Sedangkan di kelas kontrolrata-rata pretes siswa adalah 40,53 dengan standart deviasi sebesar 9,27 dan mengalami kenaikan rata-rata post-test menjadi 52,40 dengan standart deviasi sebesar 7,01 serta kenaikan rata-ratanya sebesar 11,87 dengan standart deviasi sebesar 6,03 serta memiliki persentase kenaikan sebesar $29 \%$. Untuk memperjelas hasil rata-rata pre-test dan post-test kelas kontrol dapat dilihat pada gambar histogram berikut ini:

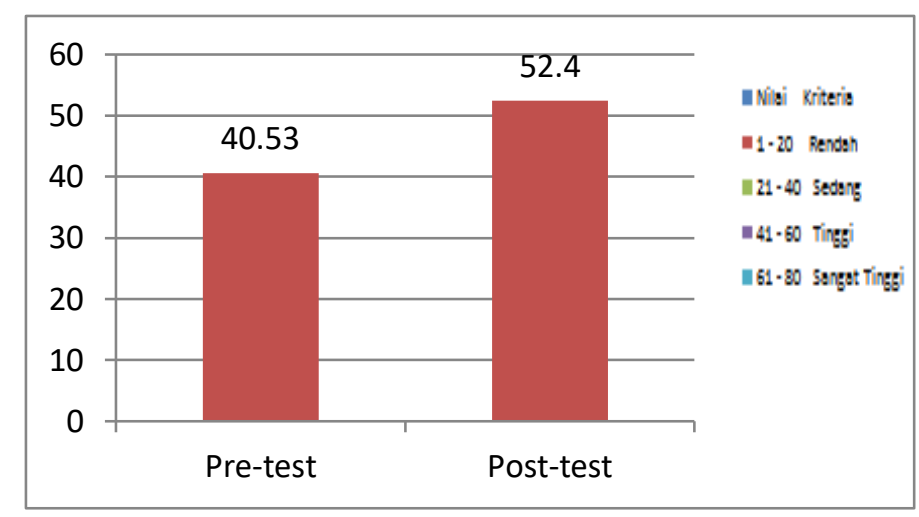

\section{Gambar 2 Rata-rata Kelas Kontrol}

Berdasarkan gambar 2 bahwa rata-rata pre-test kelas kontrol adalah 40,53 dengan kriteria sedang dan rata-rata post-test kelas kontrol adalah 52,4 dengan kriteria tinggi. Untuk melihat kriteria peningkatan kelas kontrol dapat dilihat pada tabel 6 berikut ini:

Tabel 3. Hasil N-gain Kelas Kontrol

\begin{tabular}{|c|c|c|}
\hline $\mathbf{N}$ & Indeks Gain & Kriteria \\
\hline 30 & 0,30 & Rendah \\
\hline
\end{tabular}

Berdasarkan tabel 5 indeks gain sebesar 0,30 dengan kriteria rendah yang artinya bahwa peningkatan kemampuan koneksi matematis siswa kelas XI SMA Negeri 1 Silangkitan yang diajar menggunakan model konvensional adalah rendah.

\section{Analisis Hasil Penelitian}

Berdasarkan perhitungan uji normalitas kelas eksperimen diperoleh nilai $\operatorname{sig}>$ taraf $\operatorname{sig}(\alpha=$ $0,05)$ yaitu $0,139>0,05$ yang artinya bahwa data gain kelas eksperimen berdistribusi normal. Sedangkan untuk kelas kontrol diperoleh nilai sig $>$ taraf sig yaitu 0,174 $>0,05$ yang artinya bahwa data gain kelas kontrol berdistribusi normal. Maka dapat disimpulkan bahwa data gain kelas eksperimen dan kontrol berdistribusi normal. Berdasarkan perhitungan uji homogenitas diperoleh nilai $\operatorname{sig}>$ taraf $\operatorname{sig}(\alpha=0,05)$ yaitu $0,175>0,05$ yang artinya bahwa data gain kelas eksperimen dan kelas kontrol homogen. Berdasarkan hasil uji t diperoleh nilai sig $<$ taraf $\operatorname{sig}(\alpha=0,05)$ yaitu $0,000<0,05$ maka Ho ditolak yang artinya bahwa terdapat perbedaan peningkatan hasil tes kemampuan koneksi matematis siswa kelas eksperimen dan kontrol.

Sedangkan berdasarkan hasil perhitungan $\mathrm{N}$-gain menunjukkan bahwa peningkatan kemampuan koneksi matematis siswa yang diajar menggunakan model CTL (Contextual Teaching And Learning) lebih baik daripada yang diajar menggunakan model konvensional hal ini berdasarkan hasil indeks $\mathrm{N}$-gain kelas eksperimen lebih tinggi dibandingkan dengan indeks $\mathrm{N}$-gain kelas kontrol yaitu indeks $\mathrm{N}$-gain kelas eksperimen adalah 0,53 dengan kriteria sedang dan hasil indeks $\mathrm{N}$-gain kelas kontrol adalah 0,3 dengan kriteria rendah.

\section{Pembahasan Penelitian}

Tujuan penelitian ini adalah untuk mengetahui peningkatan kemapuan koneksi matematis siswa melalui model pembelajaran CTL pada materi Permutasi dan Kombinasi kelas XIA3 dan XIA2 
SMA Negeri 1 Silangkitang dan peningkatan kemampuan koneksi matematis siswa antara kelas yang menggunakan model pembelajaran CTL dengan model pembelajaran konvensional. Penelitian ini menggunakan dua kelas yaitu kelas XIA3 sebagai kelas eksperimen dan kelas XIA2 sebagai kelas kontrol, untuk mengetahui kemampuan awal kedua kelas. Dari hasil rata-rata pre-test kelas eksperimen diperoleh rata-rata sebesar 40,87 dengan kriteria sedang dan memiliki standart deviasi 8,24 setelah diberikan perlakuan model CTL (Contextual Teaching And Learning) mengalami kenaikan rata-rata post-test menjadi 61,70 dengan kriteria sangat tinggi dan memiliki standart deviasi 7,22. Kenaikan rata-rata pada kelas eksperimen sebesar 20,83 dengan standart deviasi 7,70 dan memiliki persentase kenaikan sebesar $50,98 \%$. Kriteria peningkatan kemampuan komunikasi kelas eksperimen dilihat dari indeks gain sebesar 0,53 dengan kriteria sedang.

Sedangkan rata-rata pre-test kelas kontrol adalah 40,53 dengan kriteria sedang dan memiliki standart deviasi sebesar 9,27 setelah diberikan perlakuan model konvensional mengalami kenaikan rata-rata post-test menjadi 52,40 dengan kriteria tinggi dan memiliki standart deviasi 7,01 . Kenaikan rata-rata pada kelas kontrol sebesar 11,87 dengan standart deviasi sebesar 6,03 serta memiliki persentase kenaikan sebesar $29 \%$. Kriteria peningkatan kemampuan komunikasi kelas kontrol dilihat dari indeks gain sebesar 0,3 dengan kriteria rendah.

Hasil analisis uji t data gain kelas eksperimen dan kontrol menunjukkan bahwa nilai $s i g<$ taraf sig yaitu $0,000<0,05$ yang artinya bahwa terdapat perbedaan hasil tes kemampuan komunikasi matematis siswa kelas eksperimen dan kelas kontrol. Dengan kata lain bahwa terdapat peningkatan kemampuan komunikasi matematis siswa kelas XI SMA Negeri 1 Silangkitang tahun pembelajaran 2017/2018 yang diajar menggunakan model pembelajaran CTL (Contextual Teaching and Learning). Dilihat dari indeks gain kelas eksperimen yaitu 0,53 yang lebih tinggi dibandingkan dengan indeks gain kelas kontrol yaitu 0,3 maka model pembelajaran CTL (Contextual Teaching and Learning) lebih baik digunakan untuk meningkatkan kemampuan komunikasi matematis siswa.

\section{Kesimpulan}

Berdasarkan hasil penelitian dan pembahasan dapat disimpulkan bahwa: Model CTL (Contextual Teaching And Learning) lebih baik digunakan untuk meningkatkan kemampuan komunikasi matematis siswa dari pada model konvensional. Hal ini berdasarkan dari hasil indeks $N$ gain kelas eksperimen lebih tinggi dibandingkan dengan indeks $N$-gain kelas kontrol yaitu indeks $N$ gain kelas eksperimen adalah 0,53 dengan kriteria sedang dan hasil indeks $\mathrm{N}$-gain kelas kontrol adalah 0,3 dengan kriteria rendah.

Berdasarkan hasil penelitian dan kesimpulan yang telah dijelaskan. Maka saran peneliti adalah model pembelajaran CTL dapat digunakan guru dalam peningkatan kemampuan koneksi matematis siswa. Dalam menerapkan model pembelajaran CTL guru harus mampu menguasai model ini dengan baik, dan lebih mengkreasikan siswa dalam proses pembelajaran agar dapat berjalan dengan baik, guru juga harus bisa menguasai kelas serta mendorong siswa agar berpartisipasi aktif dalam kegiatan pembelajaran agar materi dapat dipahami siswa dengan baik dan pencapaian yang diharapkan dapat terpenuhi.

\section{Daftar Pustaka}

[1] Halomoan, Tua (2015). Penerapan Contextual Teaching And Learning Untuk Meningkatkan Kemampuan Koneksi Dan Representasi Matematika Siswa Kelas VII-2 SMP Nurhasanah Medan Tahun Pelajaran 2012/2013. Universitas Muhammadiyah Sumatera Utara

[2] Logina, Rendya Dkk (2012). Kemampuan Koneksi Matematis Dan Metode Pembelajaran Quantum Teaching Dengan Peta Pikiran. FMIPA UPN

[3] Muslim, Arifin (2014). Pengertian Kemampuan Koneksi Matematis. [Diunduh 2017 April 19] Tersedia Dari Http://Www.Google.Co.Id/Amp/S//Arifinmuslim.Wordpress.Com

[4] Srirayani (2015). Model Pembelajaran Berbasis Proyek (Project Based Learning). Universitas Negeri Medan. 
[5] Yulia, Putrid (2016). Efektifitas Model Pembelajaran CTL (Contextual Teaching And Learning) Terhadap Kemampuan Pemecahan Masalah Matematis Siswa Kelas VIII SMPN 16 Batam Tahun Pembelajaran 2014/2015. Universitas Riau Kepulauan Batam 